\title{
Substituição parcial de farelo de soja por ureia protegida na produção e composição do leite
}

[Effects of partial replacement of soybean meal by protected urea on milk yield and composition]

\author{
V.L. Souza ${ }^{1}$, R. Almeida ${ }^{2 *}$, D.F.F. Silva ${ }^{3}$, P.R.B. Piekarski ${ }^{1}$, C.P. Jesus ${ }^{4}$, M.N. Pereira ${ }^{5}$ \\ ${ }^{1}$ Aluna de pós-graduação - UFPR - Curitiba, PR \\ ${ }^{2}$ Departamento de Zootecnia - UFPR \\ Rua dos Funcionários, 1540 \\ 80035-050 - Curitiba, PR \\ ${ }^{3}$ Aluna de graduação - UFPR - Curitiba, PR \\ ${ }^{4}$ Colégio Olegário Macedo - CEAGROM - Castro, PR \\ ${ }^{5}$ Departamento de Zootecnia - UFLA - Lavras, MG
}

\begin{abstract}
RESUMO
Avaliaram-se os efeitos da ureia protegida na produção e composição do leite, utilizando-se 34 vacas da raça Holandesa, com $128 \pm 60$ dias em leite e produção de $41,6 \pm 6,7 \mathrm{~kg} /$ dia no início do experimento, distribuídas em blocos por produção de leite, ordem de lactação e dias em lactação. As variáveis produção de leite, porcentagens e produções de gordura, proteína, lactose e sólidos totais do leite, contagem de células somáticas e nitrogênio ureico no leite foram mensuradas aos 30 e 60 dias do experimento. Os dados foram analisados por procedimento de modelos mistos com o modelo contendo como covariável as observações obtidas antes da adoção das dietas experimentais e os efeitos fixos de período, de tratamento e a interação de período versus tratamento. Os tratamentos (T) foram compostos por dietas isoenergéticas e isonitrogenadas com $1,66 \mathrm{EL}_{\mathrm{L}}$ e $18,35 \%$ de $\mathrm{PB}$, definidas como: $\mathrm{T} 1=11,4 \%$ farelo de soja e T2 $=0,4 \%$ ureia encapsulada $+9,0 \%$ farelo de soja. Não foram observadas diferenças $(\mathrm{P}>0,05)$ nas produções diárias de leite e de sólidos, de nitrogênio ureico no leite e da contagem de células somáticas. A dieta com ureia protegida reduziu $(\mathrm{P}<0,05)$ as porcentagens de gordura e de sólidos totais do leite. A substituição parcial do farelo de soja por ureia protegida não reduziu o desempenho produtivo das vacas em lactação.
\end{abstract}

Palavras-chave: vaca leiteira, leite, nitrogênio ureico, nitrogênio não proteico, Optigen ${ }^{\circledR} \mathrm{II}$

\begin{abstract}
The effects of protected urea on milk yield and composition were evaluated. Thirty-four lactating Holstein cows, with $128 \pm 60$ days in milk and yield of $41.6 \pm 6.7 \mathrm{~kg} /$ day at the beginning of the trial, were blocked by milk production, lactation number, and days in milk. Milk yield; yields and contents of fat, protein, lactose, total solids; somatic cell count; and milk urea nitrogen were measured on days 30 and 60 of the comparison period. Variables measured before the application of treatments were used as covariate in the statistical model. Data were analyzed with the mixed procedure of SAS with a model containing the continuous effect of the covariate and the fixed effects of period, treatment, and the interaction of period and treatment. Treatments $(T)$ were isoenergetic and isonitrogenous diets with 1.66 $E L_{L}$ and $18.35 \%$ of $C P$, described as: $T 1=11.4 \%$ soybean meal and $T 2=0.4 \%$ encapsulated urea + $9.0 \%$ soybean meal. There was no treatment effect $(P>0.05)$ on the daily production of milk and solids, milk urea nitrogen, and somatic cell count. The slow release urea diet reduced $(P<0.05)$ milk fat and total solids contents. The partial replacement of soybean meal by protected urea did not decrease the performance of lactating cows.
\end{abstract}

Keywords: dairy cow, milk urea nitrogen, non-protein nitrogen, Optigen ${ }^{\circledR} I I$

Recebido em 18 de abril de 2009

Aceito em 11 de outubro de 2010

*Autor para correspondência (corresponding author)

E-mail: ralmeida@ufpr.br 


\section{INTRODUÇÃO}

A utilização do nitrogênio não proteico de liberação gradativa no rúmen pode ser uma estratégia para diminuir a utilização das fontes de proteína verdadeira e da ureia pecuária em dietas para ruminantes, com vantagens de diminuir os riscos de intoxicação por ureia, aumentar o espaço para inclusão de ingredientes na dieta, substituir fontes de proteína verdadeira de alto custo e/ou disponibilidade limitada, podendo ainda melhorar o sincronismo de nutrientes no rúmen, sem comprometer o desempenho produtivo de vacas leiteiras.

Em ruminantes, as bactérias celulolíticas utilizam principalmente a amônia como fonte de nitrogênio, e as bactérias fermentadoras de amido, pectina e açúcar usam tanto a amônia como peptídeos e aminoácidos (Russel et al., 1992). Com isso, dietas que proporcionem nitrogênio não proteico (NNP) e proteína verdadeira no rúmen podem melhorar a nutrição dos diferentes grupos de microrganismos ruminais, maximizando a produção de proteína microbiana.

Para a síntese de proteína microbiana e o aproveitamento do $\mathrm{N}$-amoniacal, é necessário ter disponibilidade de esqueletos de carbono em sincronia com a degradação da proteína no rúmen (Van Soest, 1994). Em dietas com baixa concentração energética, o excesso de amônia pode passar rapidamente para o sangue por difusão, alcançar o fígado, onde é convertida em ureia, e elevar os níveis de nitrogênio ureico no plasma sanguíneo, no leite, na saliva e na urina (Baker et al., 1995).

No Brasil, o farelo de soja é a principal fonte proteica em dietas para vacas leiteiras suplementadas com concentrado. A inclusão deste ingrediente pode resultar em maior custo dietético, pois sua demanda é crescente na avicultura e suinocultura intensivas e seu preço tem variação conforme o mercado internacional. A utilização de outras fontes proteicas em substituição ao farelo de soja, desde que não comprometa o desempenho animal, pode ser uma estratégia viável para a redução dos custos dietéticos do rebanho leiteiro. No entanto, essas fontes proteicas alternativas devem ser eficientes, seguras e econômicas, permitindo desempenhos produtivos similares aos animais alimentados com dietas tradicionais (Pina et al., 2006).

A substituição parcial do farelo de soja por ureia em dietas para vacas da raça Holandesa à base de cana-de-açúcar não influenciou as concentrações de proteína do leite, caseína, proteínas do soro, assim como o nitrogênio ureico do leite (Aquino et al., 2008). Já em bovinos de corte, alimentados com dieta à base de bagaço de cana-de-açúcar hidrolisado, a substituição parcial de farelo de soja por ureia ou amireia (fonte de nitrogênio de liberação gradativa) comprometem o desempenho, além de a amireia não ter se mostrado superior à ureia. Essa redução do desempenho pode ser resultado da limitação de carboidratos rapidamente fermentescíveis no rúmen e da baixa disponibilidade de proteína não degradável no rúmen (PNDR). Assim, a maior quantidade de PNDR do farelo de soja também pode ter contribuído para a síntese de proteína metabolizável, proporcionando ganhos mais elevados (Pires et al., 2008).

O aumento de NNP nas dietas de vacas leiteiras lactantes tem sido associado com reduções no consumo de matéria seca e na produção de leite corrigida para 3,5\% de gordura. Entretanto, o aumento da concentração dietética de NNP não influenciou os teores de ureia e nitrogênio ureico no plasma e no leite, assim como a dinâmica folicular ovariana pós-parto (Oliveira et al., 2004).

Efeitos positivos também têm sido descritos para vacas lactantes alimentadas com elevado teor de ureia/sulfato de amônia (5\% da MS do concentrado), em dietas à base de farelo de soja e, dentre eles, destacam-se a não alteração da produção e composição do leite, a eficiência de utilização da matéria seca e do nitrogênio para a síntese de leite, em comparação à dieta que contenha somente farelo de soja (Pina et al., 2006).

A utilização da ureia de liberação lenta pode ser outra fonte alternativa de NNP para ruminantes. Em vacas no início da lactação, o uso de ureia encapsulada em substituição à ureia comum aumentou as produções de proteína verdadeira e de gordura no leite, assim como a energia secretada no leite, mas não influenciou a composição do leite de vacas no meio da lactação (Highstreet et al., 2010). 
A utilização da ureia encapsulada para vacas lactantes, em substituição parcial ao farelo de soja, tem o potencial de diminuir o consumo de matéria seca, sem influenciar a produção de leite. Outro potencial benefício é que a ureia protegida pode ser mais eficiente na redução do nitrogênio ureico no leite comparativamente à ureia (Santos, 2009).

O objetivo do presente trabalho foi avaliar a substituição parcial de proteína verdadeira farelo de soja - por ureia encapsulada - fonte de nitrogênio não proteico de liberação lenta -, na produção e na qualidade do leite de vacas lactantes de alta produção, em dietas à base de silagem de milho.

\section{MATERIAL E MÉTODOS}

O experimento foi realizado de fevereiro a abril de 2008 e utilizou 34 vacas da raça Holandesa em lactação, com média de idade de 3,6 anos, sendo 14 primíparas e 20 multíparas, com $128 \pm 60$ dias em leite e média de produção de $41,6 \pm 6,7 \mathrm{~kg}$ de leite no início do experimento. Os animais foram sorteados em delineamento de blocos ao acaso, pareados por ordem de parição, dias em leite e produção de leite e distribuídos homogeneamente em dois grupos de 17 animais.
A instalação utilizada foi um sistema de confinamento do tipo free-stall, a alimentação foi fornecida duas vezes ao dia, ad libitum, às $10 \mathrm{~h} \mathrm{e}$ às 15h30min, na forma de dieta total misturada (TMR), com sobras de 5 a $10 \%$, sendo estas recolhidas e descartadas diariamente. Os animais já recebiam, antes do período experimental, ureia como fonte de NNP na dieta.

Os tratamentos foram: $\mathrm{T} 1=11,4 \%$ farelo de soja (controle) e $\mathrm{T} 2=0,4 \%$ ureia encapsulada (Optigen $\left.{ }^{\circledR} \mathrm{II}\right)+9,0 \%$ farelo de soja, na base da matéria seca. Em termos práticos, as vacas do T2 receberam $100 \mathrm{~g} / \mathrm{vaca} /$ dia de Optigen ${ }^{\circledR} \mathrm{II}$ no lugar de $700 \mathrm{~g} / \mathrm{vaca} /$ dia de farelo de soja, caracterizando a substituição parcial. Na Tab. 1, são apresentadas as composições percentuais das dietas T1 e T2.

As dietas foram formuladas segundo as recomendações do NRC (Nutrient..., 2001), para resultar em dietas isonitrogenadas e isoenergéticas, utilizando-se os programas Spartan Ration Evaluator (Michigan State University, Versão 2.01, 1992) e CPM-Dairy (Cornell-Penn-Miner Dairy, Versão 3.08.01, 2006). Na Tab. 2, são apresentadas a composição dos ingredientes e a composição química das dietas.

Tabela 1. Composição percentual das dietas oferecidas às vacas leiteiras

\begin{tabular}{lcc}
\hline Alimento & Controle & Optigen $^{\circledR} \mathrm{II}$ \\
\hline Silagem de milho & 30,16 & 30,58 \\
Pré-secado de azevém & 11,66 & 11,82 \\
Ração B3B Especial $^{1}$ & 30,26 & 30,68 \\
Caroço de algodão & 5,40 & 5,48 \\
Farelo de soja & 11,40 & 9,02 \\
Casca de soja & 8,36 & 9,23 \\
Optigen $^{\circledR} \mathrm{II}^{2}$ & - & 0,40 \\
Megalac-E $^{3}$ & 0,80 & 0,80 \\
Mistura mineral $^{4}$ & 1,96 & 1,99
\end{tabular}

${ }^{1}$ Composição - U: 11,0\%; PB: 21,0\%; ELlac: 1,84Mcal/kg; EE: 4,21\%; MM: 8,80\%; Ca: 1,25\%; P: 0,62\%; Cu: 25ppm; Co: 1,05ppm; I: 3,25ppm; Mn: 70ppm; Se: 0,69ppm; Zn: 146ppm; vit.A: 6000UI/kg; vit. D3: 1600UI/kg; vit.E: 55,5ppm; monensina sódica: 30ppm.

${ }^{2}$ Alltech Inc., Nicholasville, KY, EUA.

${ }^{3}$ Church \& Dwight, Princeton, NJ, EUA.

${ }^{4}$ Composição (por kg do produto) - Ca: 155,8g; P: 51,0g; S: 20,0g; Mg: 33,0g; Na: 93,0g; K: 28,2g; Co: 30ppm; Cu: 400ppm; Cr: 10ppm; Fe: 2000ppm; I: 40ppm; Mn: 1350ppm; Se: 15ppm; Zn: 1700ppm; vit.A: 135.000UI; vit.D3: 68.000UI; vit.E: 450UI. 
Tabela 2. Composição química das dietas e das forragens oferecidas às vacas leiteiras

\begin{tabular}{lcccc}
\hline Nutriente (\%MS) & Controle & Optigen $^{\circledR}$ II & Silagem de milho & Pré-secado azevém \\
\hline MS & 49,3 & 49,0 & 23,56 & 43,14 \\
PB & 18,35 & 18,35 & 8,48 & 12,25 \\
PNDR & 6,31 & 5,98 & - & - \\
EL $_{L}$ & 1,66 & 1,66 & 1,41 & 1,25 \\
NDT $^{1}$ & 72,3 & 72,3 & 62,26 & 55,87 \\
FDN & 38,4 & 39,1 & 56,91 & 63,82 \\
FDA & 22,8 & 23,2 & 31,60 & 37,48 \\
CNF $^{2}$ & 30,7 & 30,5 & 28,09 & 15,08 \\
EE & 4,8 & 4,8 & 3,15 & 2,57 \\
Cálcio & 1,02 & 1,03 & 0,24 & 0,45 \\
Fósforo & 0,54 & 0,53 & 0,16 & 0,20 \\
\hline
\end{tabular}

${ }^{1}$ Estimado usando a equação de Weiss (Nutrient..., 2001).

${ }^{2}$ Carboidratos não fibrosos $=100-($ PB + FDN + EE + RM $)$.

MS: matéria seca; PB: proteína bruta; PNDR: proteina não degradável no rúmen; EL: energia líquida; NDT: nitrogênio digestível total; FDN: fibra em detergente líquido; FDA: fibra em detergente ácido; CNF: carboidratos não fibrosos; EE: extrato etéreo.

Amostras dos alimentos volumosos foram coletadas no início e no final do experimento, pré-secas em estufa de ventilação forçada a 60$65^{\circ} \mathrm{C}$, por 72 horas, e moídas em moinho estacionário Wiley Miller, utilizando-se peneira de malha de $1 \mathrm{~mm}$. Foram realizadas determinações de matéria seca (MS), proteína bruta (PB), extrato etéreo (EE), resíduo mineral $(\mathrm{RM})$, cálcio $(\mathrm{Ca})$ e fósforo $(\mathrm{P})$, segundo o AOAC (Official..., 1990), e fibra em detergente neutro (FDN), fibra em detergente ácido (FDA) e lignina (Van Soest et al., 1991). O escore da condição corporal foi determinado pelo mesmo avaliador no início e no final do experimento.

As vacas foram ordenhadas três vezes ao dia, às $5 \mathrm{~h}$, às $12 \mathrm{~h}$ e $45 \mathrm{~min}$ e às $19 \mathrm{~h}$ e $45 \mathrm{~min}$, com a utilização de ordenhadeira mecânica. As amostras de leite foram coletadas durante o controle leiteiro oficial realizado pelo Programa de Análise de Rebanhos Leiteiros do Paraná (PARLPR), da Associação Paranaense de Criadores de Bovinos da Raça Holandesa (APCBRH) em Curitiba, Paraná. As amostras foram condicionadas em frascos plásticos, com capacidade de $60 \mathrm{~mL}$, com conservante bronopol, e encaminhadas ao Laboratório Centralizado da APCBRH.

No laboratório, as amostras foram analisadas para gordura, proteína, lactose e sólidos totais no equipamento Bentley $2000 \quad$ (Bentley Instruments ${ }^{\circledR}$ ), pelos sistemas ópticos e infravermelhos. A contagem de células somáticas (CCS) foi determinada no equipamento Somacount (Bentley Instruments ${ }^{\circledR}$ ), por meio de citometria de fluxo. Para a análise de ureia do leite (NUL), foi utilizado o Chemspec 150 (Bentley Instruments ${ }^{\circledR}$ ), pela metodologia de Berthelot.

Os dados iniciais de produção de leite, produções e porcentagens de gordura, produções e porcentagens de proteína, produções e porcentagens de lactose, produções e porcentagens de sólidos totais, NUL, energia secretada no leite (Mcal/dia) e CCS foram incluídos no modelo como covariáveis. Todas as variáveis produtivas foram mensuradas aos 30 e 60 dias do período experimental e analisadas pelo procedimento MIXED do SAS/2003. Além da covariável (medição da mesma variável obtida antes da aplicação dos tratamentos), também foram incluídos no modelo os efeitos fixos de período, de tratamento e a interação de período versus tratamento.

O quadrado médio do efeito de vaca dentro de tratamento foi utilizado como medida de erro para testar o efeito de tratamento. Para a CCS, foi realizada uma transformação logarítmica em base decimal (log (CCS)). O escore de condição corporal (ECC) foi mensurado no início e no final do experimento e analisado pelo procedimento GLM do SAS (SAS, 2003). O modelo foi similar ao descrito acima, mas sem o efeito de período e sua interação com tratamento. 


\section{RESULTADOS E DISCUSSÃO}

Os resultados obtidos para produção de leite, produção e porcentagem de gordura, produção e porcentagem de proteína, produção e porcentagem de lactose, produção e porcentagem de sólidos totais, NUL, energia secretada no leite (Mcal/dia), log CCS e mudança no ECC são apresentados na Tab. 3. O efeito das interações tratamento versus período não foi significativo $(\mathrm{P}>0,05)$ para todas as variáveis analisadas.

Tabela 3. Médias ajustadas para produção de leite, produções e porcentagens de componentes, nitrogênio ureico do leite, energia secretada no leite, log da contagem de células somáticas (CCS) e mudança no escore de condição corporal (ECC), de acordo com os tratamentos e períodos de avaliação

\begin{tabular}{|c|c|c|c|c|c|c|c|}
\hline \multirow[t]{2}{*}{ Variável } & \multicolumn{2}{|c|}{ Farelo de soja } & \multicolumn{2}{|c|}{ Optigen ${ }^{\circledR} \mathrm{II}$} & \multirow[t]{2}{*}{ EPM } & \multirow{2}{*}{$\begin{array}{c}P \\
\text { Trat }\end{array}$} & \multirow[t]{2}{*}{$P$ Período } \\
\hline & $30 \mathrm{~d}$ & $60 \mathrm{~d}$ & $30 \mathrm{~d}$ & $60 \mathrm{~d}$ & & & \\
\hline Produção de leite (kg/dia) & 36,9 & 36,4 & 39,4 & 38,1 & 1,11 & 0,16 & 0,15 \\
\hline Porcentagem de gordura & 3,16 & 2,99 & 2,87 & 2,71 & 0,07 & $<0,01$ & 0,01 \\
\hline Produção de gordura (kg/dia) & 1,14 & 1,13 & 1,12 & 1,04 & 0,04 & 0,24 & 0,13 \\
\hline Porcentagem de proteína & 3,12 & 2,82 & 3,03 & 2,79 & 0,04 & 0,21 & $<0,01$ \\
\hline Produção de proteína (kg/dia) & 1,14 & 1,07 & 1,19 & 1,08 & 0,03 & 0,51 & $<0,01$ \\
\hline Porcentagem de lactose & 4,58 & 4,72 & 4,64 & 4,80 & 0,03 & 0,08 & $<0,01$ \\
\hline Produção de lactose (kg/dia) & 1,70 & 1,73 & 1,83 & 1,84 & 0,06 & 0,13 & 0,55 \\
\hline Porcentagem de sólidos & 11,74 & 11,43 & 11,43 & 11,21 & 0,10 & 0,04 & $<0,01$ \\
\hline Produção de sólidos (kg/dia) & 4,31 & 4,19 & 4,47 & 4,25 & 0,12 & 0,46 & 0,04 \\
\hline Nitrogênio ureico no leite (mg/dL) & 22,4 & 11,7 & 23,5 & 12,1 & 1,24 & 0,59 & $<0,01$ \\
\hline Energia do leite (Mcal/dia) & 23,6 & 22,6 & 24,1 & 22,5 & 0,62 & 0,77 & $<0,01$ \\
\hline Log CCS & 3,14 & 2,73 & 2,85 & 1,82 & 0,29 & 0,10 & $<0,01$ \\
\hline ECC mudança (pontos) & - & 2,57 & - & 2,65 & 0,04 & 0,23 & - \\
\hline
\end{tabular}

A produção de leite não foi influenciada $(\mathrm{P}>0,05)$ pelo tratamento. No presente estudo, os resultados evidenciam que a utilização de ureia de liberação lenta, em substituição parcial ao farelo de soja, não reduz o desempenho produtivo de vacas leiteiras de alta produção, alimentadas com dieta à base de silagem de milho.

Santos (2009), ao compar a substituição parcial do farelo de soja por polpa cítrica e duas fontes de nitrogênio não proteico (ureia encapsulada e ureia comum) em vacas em lactação, usando a mesma fonte de ureia protegida (Optigen ${ }^{\circledR} \mathrm{II}$ ), não encontrou diferenças na produção de leite, assemelhando-se aos resultados apresentados na Tab. 3.

Resultados similares foram encontrados em diversos trabalhos sumarizados por Santos et al. (1998), envolvendo 23 comparações de 12 trabalhos, que avaliaram os efeitos da inclusão parcial ou total da ureia em dietas para vacas de alta produção. Os autores verificaram que em 20 comparações a produção de leite permaneceu inalterada e somente diminuiu em três comparações. Estes resultados também assemelham-se aos de Pina et al. (2006), mas diferem dos observados por Oliveira et al. (2004), que verificaram redução na produção de leite corrigida para $3,5 \%$ de gordura com o aumento do NNP nas dietas de vacas mestiças.

No estudo de Highstreet et al. (2010), realizado em vacas de alta produção que recebiam dietas à base de silagem de milho e farelo de canola, não foi verificada a superioridade da ureia encapsulada em relação à ureia pecuária na produção de leite. Santos (2009) também não encontrou diferença na produção de leite de vacas alimentadas com ureia pecuária e ureia encapsulada. Este fato é relevante, pois as fontes de ureia de liberação lenta apresentam maior custo comparado ao da ureia comum.

A suplementação de ureia protegida diminuiu as porcentagens de gordura $(\mathrm{P}<0,01)$ e de sólidos do leite $(\mathrm{P}<0,05)$, no entanto não afetou $(\mathrm{P}>0,05)$ as produções de gordura e de sólidos totais (Fig. 1 e Tab. 3). Os resultados do presente estudo divergem dos obtidos por Santos (2009) e Galo et al. (2003), os quais não encontraram diferenças para porcentagem de gordura entre animais tratados ou não com ureia protegida. 


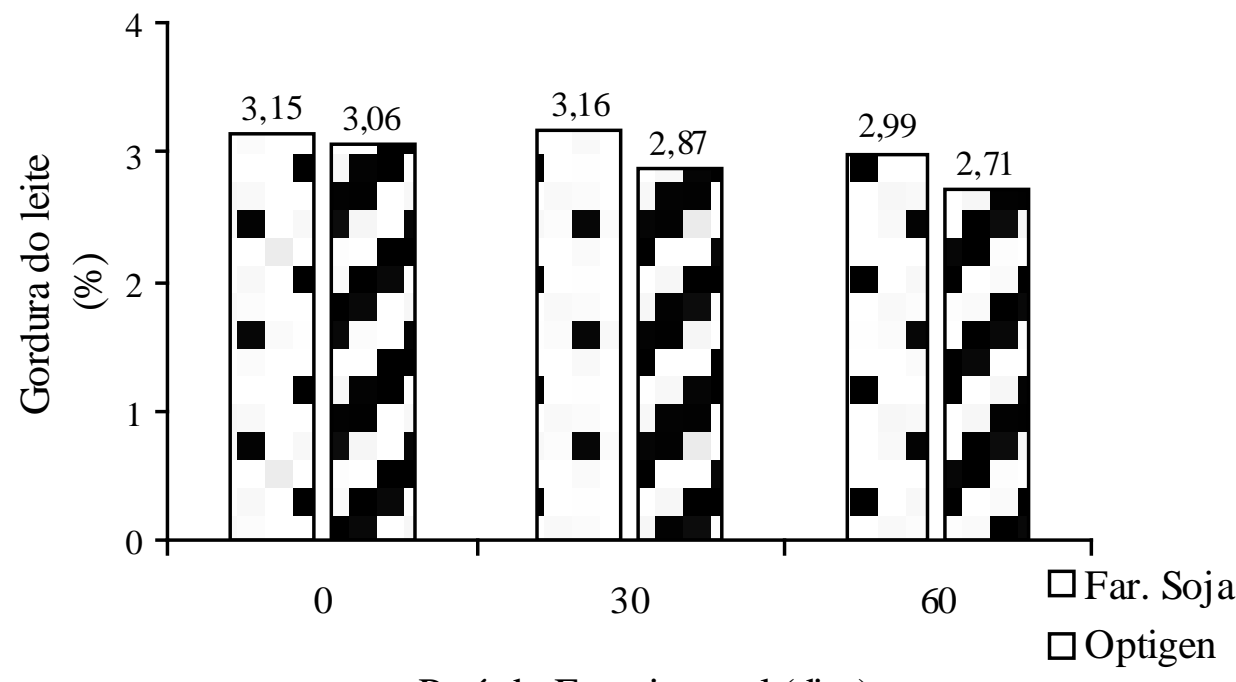

Período Experimental (dias)

Figura 1. Porcentagem de gordura no leite de vacas controle e tratadas com ureia protegida Optigen ${ }^{\circledR} \mathrm{II}$ durante o período experimental.

Segundo Highstreet et al. (2010), o uso de ureia encapsulada pode promover um pequeno aumento na gordura no leite em vacas leiteiras, em relação à ureia não protegida. O aumento da síntese de gordura do leite em vacas alimentadas com ureia encapsulada pode ser atribuído à diminuição dos picos de concentração de amônia ruminal, o que pode ter impactado as proporções de ácidos graxos voláteis produzidos no rúmen e, assim, influenciado a síntese da gordura do leite. Já em novilhos, a utilização de ureia encapsulada no suplemento proteico, em dieta à base de volumosos de baixa qualidade, não resultou em mudanças na concentração de nitrogênio amoniacal no rúmen, nos valores de $\mathrm{pH}$ e na degradabilidade in situ, em relação à ureia comum (Azevedo et al., 2010).

No presente estudo, a comparação entre a ureia protegida e a ureia pecuária não foi realizada, entretanto Santos (2009) não obteve melhora na produção e porcentagem de gordura do leite, e nem da digestibilidade da fibra em detergente neutro, quando utilizou ureia encapsulada comparativamente à ureia para vacas leiteiras.

Segundo Bauman e Griinari (2003), a queda do teor de gordura do leite é devido à presença de uma fermentação anormal no rúmen, com diminuição do $\mathrm{pH}$ ruminal, ocasionada pelo fornecimento de dietas de baixa fibra e/ou excesso de concentrado, ou ainda devido à presença de gordura insaturada na dieta. A queda do $\mathrm{pH}$ ruminal pode alterar as rotas de bioidrogenação ruminal, produzindo um ácido graxo específico (CLA trans-10 cis-12), e sua concentração aumentada promove redução da secreção de ácidos graxos de cadeias curta e média, provenientes da síntese de novo de ácidos graxos.

Os possíveis mecanismos que resultaram na diminuição do teor de gordura do leite de vacas alimentadas com ureia encapsulada não foram elucidados, uma vez que a dieta base ofertada aos animais foi semelhante entre os tratamentos, e supria as exigências de fibra fisicamente efetiva das vacas. Testes de degradabilidade ruminal da fibra e proporção de ácidos graxos voláteis são sugeridos em futuras pesquisas de vacas lactantes alimentadas com ureia encapsulada.

Não houve diferenças $(\mathrm{P}>0,05)$ entre os tratamentos para produção e porcentagem de proteína, bem como para energia secretada no leite (Tab. 3), resultados semelhantes aos obtidos por Santos (2009) e Galo et al. (2003), quando avaliaram o efeito da ureia protegida para vacas em lactação. Já Highstreet et al. (2010) 
observaram efeito positivo na secreção de proteína verdadeira e energia do leite, com a inclusão de ureia protegida na dieta, em comparação com a adição de ureia comum.

O maior fornecimento de ureia para vacas leiteiras com a finalidade de aumentar o teor de proteína dietética de 16 para 17,5\%, em dietas à base de silagem de milho e farelo de soja, pode comprometer o teor de proteína do leite (Imaizumi et al., 2010), diferente do que foi obtido no presente estudo, pois a inclusão de ureia protegida não diminuiu a síntese de proteína do leite.

Os valores de NUL não foram afetados $(\mathrm{P}>0,05)$ com a suplementação de ureia protegida, mas houve aumento significativo $(\mathrm{P}<0,01)$ da variável NUL no dia 30 do período experimental. A análise de nitrogênio ureico do leite é uma ferramenta valiosa para o monitoramento dos níveis de proteína da dieta (Hof et al., 1997). Os valores semelhantes de NUL entre os tratamentos podem ser explicados pela composição isonitrogenada das dietas e também sugerem que a velocidade de liberação do nitrogênio na ureia protegida Optigen ${ }^{\circledR}$ II foi similar à verificada no farelo de soja.

O aumento de nitrogênio não proteico nas dietas de vacas leiteiras não influenciou os teores de nitrogênio no leite no experimento de Oliveira et al. (2004), aspecto confirmado com os resultados obtidos no presente estudo. Entretanto, Imaizumi et al. (2010) afirmaram que a inclusão de ureia para aumentar a proteína dietética de vacas leiteiras, em dietas à base de farelo de soja e silagem de milho, pode ter o potencial de aumentar o NUL. No trabalho de Santos (2009), com dieta base de $15,5 \%$ de proteína bruta, o NUL foi semelhante entre o grupo que recebeu somente o farelo de soja e a ureia protegida, mas o grupo tratado com ureia aumentou o NUL, comparado à ureia encapsulada e ao farelo de soja.

O aumento do NUL nos 30 dias após o início do experimento pode estar relacionado com a abertura de um novo silo de milho, e o fato de esse material ter pouco tempo de ensilagem pode ter comprometido a disponibilidade energética desta silagem e, por consequência, comprometido o sincronismo desejável entre amônia e energia no rúmen (Casper et al., 2008).
Além disso, salienta-se que os níveis dietéticos de proteína bruta de ambas as dietas foram altos (18,3\%PB), com o propósito de garantir que os níveis de proteína não degradável no rúmen não limitassem a produção, mesmo que com isso os teores de proteína degradável no rúmen fossem excessivos.

As médias ajustadas para CCS linear não diferiram $(\mathrm{P}>0,05)$ entre os tratamentos, nas condições locais do experimento, mas apresentaram diferenças $(\mathrm{P}<0,01)$ entre os dois períodos do estudo (Tab. 3). Também não foram verificadas diferenças $(\mathrm{P}>0,05)$ para mudança no ECC entre o início e o final do experimento.

\section{CONCLUSÃO}

A substituição parcial do farelo de soja por ureia protegida mostrou-se como alternativa na nutrição proteica, pois não influenciou no desempenho produtivo de vacas leiteiras de alta produção.

\section{AGRADECIMENTOS}

Centro Estadual de Educação Profissional Olegário Macedo, Winston Giardini, Marcelo Manella, Huibert Janssen, Renato Nogueira e André Hampf, pela viabilização e pelo apoio científico na execução do experimento.

\section{REFERÊNCIAS BIBLIOGRÁFICAS}

AQUINO , A.A.; LIMA, Y.V.R.; BOTARO, B.G. et al. Effects of dietary urea levels on milk protein fractions of Holstein cows. Anim. Feed Sci. Technol., v.140, p.191-198, 2008.

AZEVEDO, E.B.; PATINO, H.O.; SILVEIRA, A.L.F. et al. Suplementação nitrogenada com ureia comum ou encapsulada sobre parâmetros ruminais de novilhos alimentados com feno de baixa qualidade. Cienc. Rural, v.40, p.622-627, 2010.

BAKER, L.D.; FERGUSON, J.D.; CHALUPA, $\mathrm{W}$. Responses in urea and true protein of milk to different protein feeding schemes for dairy cows. J. Dairy Sci., v.78, p.2424-2434, 1995.

BAUMAN, D.E.; GRIINARI, J.M. Nutritional regulation of milk fat synthesis. Annu. Rev. Nutr., v.23, p.203-227, 2003. 
CASPER, D. P.; SCHAUFF, D.; KLEINSCHMIT, D. et al. The source and degradability of dietary starch influences forage and fiber utilization by lactating dairy cows. In: ADSA-ASAS JOINT ANNUAL MEETING, 2008, Indianapolis. Proceedings... Indianapolis: American Dairy Science Association, 2008. J. Dairy. Sci., v.91, E-Suppl.1, p.115, 2008. (Resumo).

GALO, E.; EMANUELE, S.M.; SNIFFEN, C.J. et al. Effects of a polymer-coated urea product on nitrogen metabolism in lactating Holstein dairy cattle. J. Dairy Sci., v.86, p.2154-2162, 2003.

HIGHSTREET, A.; ROBINSON, P.H.; ROBISON, J. et al. Response of Holstein cows to replacing urea with a slowly rumen released urea in a diet high in soluble crude protein. Livest. Sci., v.129, p.179-185, 2010.

HOF, G.; VERVOORN, M.D.; LENAERS, P.J. et al. Milk urea nitrogen as a tool to monitor the protein nutrition of dairy cows. J. Dairy Sci., v.80, p.3333-3340, 1997.

IMAIZUMI, H.; SANTOS, F.A.P; BITTAR, C.M.M. et al. Diet crude protein content and sources for lactating dairy cattle. Sci. Agric., v.67, p.16-22, 2010.

NUTRIENT requirements of dairy cattle. 7.ed. Washington, DC.: National Academy of Sciences, 2001.

OFFICIAL methods of analysis. 15.ed. Washington, DC: AOAC, 1990.

OLIVEIRA, M.M.N.F.; TORRES, C.A.A.; VALADARES FILHO, S.C. et al. Ureia para vacas leiteiras no pós-parto: Desempenhos produtivo e reprodutivo. Rev. Bras. Zootec., v.33, supl.3, p.2266-2273, 2004.
PINA, D.S.; VALADARES FILHO, S.C.; VALADARES, R.F.D. et al. Consumo e digestibilidade aparente total dos nutrientes, produção e composição do leite de vacas alimentadas com dietas contendo diferentes fontes de proteína. Rev. Bras. Zootec., v.35, p.1543-1551, 2006.

PIRES, A.V.; OLIVEIRA JUNIOR, R.C.; SUSIN, I. et al. Fontes nitrogenadas em rações contendo bagaço de cana-de-açúcar hidrolisado no desempenho de bovinos confinados em terminação. Arq. Bras. Med. Vet. Zootec., v.60, p.163-168, 2008.

RUSSELL, J.B.; O’CONNOR, J.D.; FOX, D.G et al. A net carbohydrate and protein system for evaluating cattle diets. I. Ruminal fermentation. J. Anim. Sci., v.70, p.3551-3561, 1992.

SANTOS, F.A.P.; SANTOS, J.E.P.; THEURER, C.B. et al. Effects of rumen-undegradable protein on dairy cow performance: A 12-year literature review. J. Dairy Sci., v.81, p.3182-3213, 1998.

SANTOS, J.F. Respostas de vacas leiteiras à substituição parcial de farelo de soja por ureia encapsulada. 2009. 66f. Dissertação (Mestrado) - Universidade Federal de Lavras, Lavras, MG.

VAN SOEST, P.J. Nutritional ecology of the ruminant. 2.ed. Ithaca: Cornell University, 1994.

VAN SOEST, P.J.; ROBERTSON, J.B.; LEWIS, B.A. Methods for dietary fiber, neutral detergent fiber, and nonstarch polysaccharides in relation to animal nutrition. J. Dairy Sci., v.74, p.35833597, 1991. 